\title{
The co-option of audiences in the attention economy Introduction
}

\author{
Ana Jorge*, Inês Amaral**, David Mathieu*** \\ *Universidade Católica Portuguesa, Portugal \\ **Faculdade de Letras da Universidade de Coimbra, Portugal \\ ***Roskilde University, Denmark
}

The motivation for this special issue was born of the two-day conference 'Audiences 2030: Imagining a future for audiences', in late September 2017, in Lisbon, sponsored by the Consortium on Emerging Directions of Audience Research (CEDAR) which was funded by the Arts and Humanities Research Council, UK, in association with Universidade Católica Portuguesa, as well as the Audience and Reception Studies section of ECREA and YECREA. The event was the public culmination of the three-year work of CEDAR, directed by Ranjana Das (University of Surrey) and Brita Ytre-Arne (University of Bergen). The network identified as one of the major trends in audience and audience research that audience participation is being co-opted by large, global players, partly as a consequence of the technological capabilities developed by digital media (Das \& Ytre-Arne, 2017).

Recent debates on datafication and exploitation have looked at digital workers as well as at audiences in different degrees of creativity and productivity, displayed by fans in their remediation of media content, by produsers (Bruns, 2006) in their ordinary practice of consumption or in the labor that amateurs invest in content creation. These debates have decried how platforms are able to feed the algorithms and turn audience's work and engagement into commodities for attracting attention, metrics to be sold to advertisers and business models to run social media (Hearn \& Schoenhoff, 2016). The capitalization or exploitation of audience (free) labor in the benefit of industries has been vividly argued by scholars from political economy of communication and in particular of the web 2.0 (Andrejevic, 2009; Fuchs \& Sevignani, 2013; Van Dijck, 2013; Nieborg \& Poell, 2018). In contrast, cultural studies have tended to conceptualize users' productivity as prosumption (Bruns, 2006) or participation (Jenkins, 2006; Jenkins \& Carpentier, 2013), discussing the possible gains of agency among audiences.

However, Vesnić-Alujević \& Murru (2016) claimed the urgency to reconcile the two strands of theory. In reviewing work on the topic and offering a stance for the future of audience research, Stehling et al. (2018) argue such an integrated view is crucial to understand the negotiation of power and agency between platforms and digital players, on the one hand, and audiences, on the other. Such a perspective is also crucial to make sense of the ambiguous and relatively inconsequential (for most users) critical opinions regarding media and cultural objects, and their search for, or appreciation of, recognition by industries about their creativity, e.g. among fans. Distinguishing user-generated content (UGC) as data (liking, tagging, etc.) or labor (work, content creation), the authors (2018, p. 80) argue that audience co-option can be obtained more or less voluntarily, more or less consciously, ranging from endorsement via "illegible and lengthy privacy policies and terms of use and services" to the reception of payment or other benefits in return for favorable recommendations of products and services.

Copyright (c) 2018 (Ana Jorge, Inês Amaral, David Mathieu). Licensed under the Creative Commons Attribution-NonCommercial Generic (cc by-nc). Available at http://obs.obercom.pt. 
The co-option of audiences is also an evolving practice to which they respond to, favorably or not, consciously or not, and which affects in return the conditions by which media aim to benefit from their engagement. In other words, this co-option is a site of negotiation and the outcome of this negotiation is currently being molded in a diversity of contexts involving audience engagement, from blogs to other platforms. As Sonia Livingstone and Amanda Third stated, the "digital environment may be in its infancy in terms of the evolution of social norms, but it is developing apace in its capacity to commodify its users" (2017, p. 665). Thus, this special issue sets out the goal of discussing further the dialectic nature of co-option of audience creativity especially among blogging and vlogging platforms such as YouTube, Facebook, Instagram etc., a field growing amid professionalization (Abidin, 2015; Marwick, 2015). boyd reminds us that media users, as both consumers and producers, "find themselves embedded in the attention economy" (2010, p. 53) as increasingly users are relied upon and compete with each other to reach other users or provide commercial value. Within the blogosphere, some users are profiting from this new attention economy. However, "while a niche group may achieve visibility that resembles 'micro-celebrity' (Senft, 2008), only a small fraction receives mass attention, while many more receive very small, localized attention. Scalability in networked publics is about the possibility of tremendous visibility, not the guarantee of it" (boyd, 2010, p. 48, original italics). Brooke Erin Duffy considers that digital cultural production involves a great part of uncompensated work which she calls 'aspirational labor', where work and leisure are combined in the expectation "that they will one day be compensated for their productivity" (2015, p. 4).

While user-generated content such as blogging or vlogging is a clear sign of audience agency, there is an increased tendency for that work to be co-opted by private and public media, possibly leading to new forms of power imbalance between media and audiences. We further this discussion by asking how is commodification of audience creativity intertwined with agency, or orientation to community (Hunter, 2016 on professional mommy bloggers). How do popular and professional or semi-professional 'microcelebrities' accommodate commercial communication? How do they negotiate their role in commodifying 'ordinary' users and retaining an image of integrity and authenticity (Cunningham \& Craig, 2017)?

Not only is the objective of this special issue to provide new empirical ground for the discussion of these issues, but we also aim to go beyond the Anglo-Saxon treatment of the topic and provide research that also shows the transnational character of these phenomena, as well as the entanglement of audience practices and its co-option in larger discourses and practices that transcend specific locations. This variety is needed to show the extent of co-option and its various logics, but also to reveal the specificities of local and cultural appropriation and negotiation, as well as the differing conditions in which audiences can be exploited or protected, can benefit from co-option or are made vulnerable. This special issue has collected a variety of empirical researches of cases belonging to under-researched and under-represented countries such as Romania, Spain, Portugal, Estonia, Turkey and Italy.

This special issue includes six original articles, which cross different theoretical perspectives and present empirical studies from several contexts. The article by Marco Pedroni and Maria Paola Pofi, "Commodifying the followers or challenging the mainstream? A misleading antinomy examined through the work of curvy fashion bloggers and their relationship with the audience", explores the process of co-evolution of digital influencers and audiences, considering the work of female curvy fashion bloggers. Anchored in both cultural studies and political economy, the article demonstrates that the audience of digital influencers is commodified as a source of economic income and to mobilize symbolic capital, using the argument of "challenge to 
the mainstream" while exploring the commercialization of public attention. Monica Lungeany and Lorenza Parisi also explore fashion bloggers and the way they build their online personas in Instagram. The authors develop a content analysis of seven of the top Romanian fashion bloggers' accounts, presenting a typology of this kind of UGC that allows them to show how bloggers act as: 1) opinion leaders and trendsetters; 2) interactive and collaborative personas; and 3) 'authentic' content creators.

The article "The food chain of YouTubers: engaging audiences with formats and genres" by Marju HimmaKadakas, Allan Rajavee, Maarja-Liis Orgmets, Linda Eensaar and Ragne Kõuts-Klemm, analyzes YouTubers' content production strategies to attract young audiences. The authors develop a model of analysis based on the uses and gratifications approach to study what they call the "food chain" - the copying of innovative ideas by less experienced peers - of different levels of top YouTubers in the world. The results demonstrate how the most popular YouTubers generate new production practices and discursive genres to sustain and increase audiences, providing an interesting case in which a niche of few active users shares the same ambitions than the industry with its co-opting practices. Ana Jorge, Lidia Marôpo and Thays Nunes also focus on YouTube, although in this case to study microcelebrities and the integration of branded content within youth digital culture. The authors develop a case study on a successful young Portuguese youtuber to examine how digital producers incorporate brand culture and how the audience negotiates the meanings of the commercialism that emerges in both sponsored content and in content that, without being clearly sponsored, relates to a world at the intersection of commercialism and youth culture.

The article by Marian Blanco-Ruiz and Clara Sainz de Baranda, "Gender identity on YouTube: Case Study of LGBTIQ channels in Spain", explores and analyzes the content of the YouTube channels of the most popular LGBT+ YouTubers among Spanish young people to assess whether there are gender biases in their content. The findings reveal that content created by these YouTubers is more diverse than mainstream channels, providing an opportunity for LGBT+ audiences to find referents and to feel recognized. Looking at the television industry, Sevda Ünal, Mutlu Binark and Selin Çetindağ examine the transformation of broadcasting by second screen consumption and the resulting new broadcasting ecosystem through the case of the Turkish serial Insider. Through this case study, the authors analyze the participation of the audience as producer and consumer, the changing industry strategy, and the emergent practices of brand integration in this new broadcasting environment. The results support the argument that audiences have solidified their position as producer and consumer in the new broadcasting ecosystem.

Finally, the special issue also includes a book review on "ComMODify - User Creativity at the Intersection of Commerce and Community" by Shenja van der Graaf, from 2018. The publication of this book is timely with regard to this special issue, discussing the dynamics of content creation between communities and industry in Second Life.

The editors of the special issue would like to thank Tiago Lima for his kind assistance and guidance throughout the process of putting this issue together.

\section{References}

Abidin, C. (2015). Communicative intimacies: Influencers and perceived interconnectedness. Ada: A Journal of Gender, New Media, and Technology, 8. http://adanewmedia.org/2015/11/issue8-abidin/ 
Andrejevic, M. (2009). Exploiting YouTube: Contradictions of User-Generated Labor. In: P. Snickars \& P. Vunderau, Eds. The YouTube Reader (pp. 406-423). Stockholm: Mediehistoriskt.

boyd, d. (2010). Social network sites as networked publics: Affordances, dynamics, and implications. In Z. Papacharissi (Ed.), A Networked Self: Identity, Community, and Culture on Social Network Sites (pp. 39-58). London: Routledge.

Bruns, A. (2006). Towards Produsage: Futures for User-Led Content Production. In F. Sudweeks, H. Fay \& C. Ess (Eds.), Cultural Attitudes towards Communication and Technology 2006, 28 June - 1 July, Tartu, Estonia.

Cunningham, S., \& Craig, D. (2017). Being 'really real' on YouTube: authenticity, community and brand culture in social media entertainment. Media International Australia, 164(1), 71-81.

Das, R., \& Ytre-Arne, D. (2017). Audiences, towards 2030: Priorities for audience analysis. Surrey: CEDAR. http://epubs.surrey.ac.uk/842403/7/For\%20web\%20CEDAR-report.pdf

Van Dijck, J. (2013). The Culture of Connectivity: A Critical History of Social Media. Oxford University Press.

Duffy, B. E. (2015). The romance of work: Gender and aspirational labour in the digital culture industries. International Journal of Cultural Studies, 19(4), 441-457.

Fuchs, C., \& Sevignani, S. (2013). What is digital labour? What is digital work? What's their difference? And why do these questions matter for understanding social media? TripleC, 11(2), 237-293.

Hearn, A., \& Schoenhoff, S. (2016). "From Celebrity to Influencer: Tracing the Diffusion of Celebrity Value across the Data Stream". In P. D. Marshall \& S. Redmond (eds.), A Companion to Celebrity (pp. 194-212). Malden, MA and Oxford: Wiley Blackwell.

Hunter, (2016). Monetizing the mommy: mommy blogs and the audience commodity. Information, Communication \& Society, 19(9), 1306-1320.

Jenkins, H. (2006). Convergence culture: Where old and new media collide. New York: New York University Press.

Jenkins, H., \& Carpentier, N. (2013). Theorizing participatory intensities: A conversation about participation and politics. Convergence: The International Journal of Research into New Media Technologies, 19(3), 265-286.

Livingstone, S. \& Third, A. (2017). Children and young people's rights in the digital age: An emerging agenda. New Media \& Society, 19(5): 657-670.

Marwick, A. (2015). You may know me from YouTube: (Micro-)celebrity in social media. In S. Redmond \& P. D. Marshall (Eds.), A Companion to Celebrity (pp. 333-349). Chichester: Wiley Blackwell.

Nieborg, D. B., \& Poell, T. (2018). The platformization of cultural production: Theorizing the contingent cultural commodity. New Media \& Society, https://doi.org/10.1177/14614444818769694.

Stehling, M., Vesnic-Alujevic, L., Jorge, A., \& Marôpo, L. (2018). The co-option of audience data and usergenerated content: the empowerment and exploitation of audiences through algorithms, produsage and crowdsourcing. In R. Das \& B. Ytre-Arne (Eds.), The Future of Audiences (pp. 79-99). Basingstoke: Palgrave McMillan.

Vesnić-Alujević, L., \& Murru, M. F. (2016). Digital audiences' disempowerment: Participation or free labour. Participations. Journal of Audience \& Reception Studies, 13(1), 422-430. 